\title{
Hypothalamic Hypothyroidism
}

National Cancer Institute

\section{Source}

National Cancer Institute. Hypothalamic Hypothyroidism. NCI Thesaurus. Code C121741.

Hypothyroidism due to dysfunction of the hypothalamus, assumed to result in reduced secretion of thyrotropin- releasing hormone. 